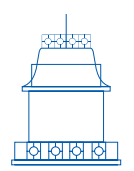

ARTÍCULOS

DE INVESTIGACIÓN

\title{
El salto del pensar: la actitud fenomenológica que nos distancia del errante trajinar metafísico*
}

\author{
Juan Sebastián Ortiz López \\ Universidad Santo Tomás, Bogotá, Colombia \\ E-mail: camusjsol@hotmail.com \\ Recibido: 31 de mayo de 2019 | Aprobado: 26 de noviembre de 2019 \\ https://doi.org/10.17533/udea.ef.n61a07
}

Resumen: En el pensamiento tardío de Heidegger resalta su constante alusión a una forma de pensar que se diferencia de la metafísica. Mientras que en el pensar metafísico nos mantenemos errando alejados del ser, en el nuevo pensar solo estamos en relación con el ser. Para Heidegger la única vía para salir del primero y llegar al segundo es a través de un salto. En este documento se pretende aclarar por qué solo hay una vía de acceso al nuevo pensar, y defender que dicha vía es una radicalización de la máxima fenomenológica. Para tal fin se parte de la caracterización del pensar metafísico como un pensar errante, se sigue con la caracterización del salto, entendido como un paso súbito al desocultamiento del ser, y se termina con las consecuencias de estas caracterizaciones y del contraste entre ambas.

Palabras clave: Heidegger, pensar, metafísica, salto, errar

* El artículo brota de las lecturas y discusiones realizadas al interior del Grupo de Investigación "La hermenéutica en la discusión filosófica contemporánea”, reconocido por COLCIENCIAS en la categoría C, código COL0064191. Una primera versión fue presentada como ponencia en el VII Congreso Colombiano de Filosofía, que se llevó a cabo en Bucaramanga del 15 a 18 de agosto de 2018.

Cómo citar este artículo:

Oriz López, J. S. (2020). El salto del pensar: la actualidad fenomenológica que nos distancia del errante trajinar metafísico. Estudios de filosofía, 61, 91-106. https://doi.org/10.17533/udea.ef.n61a07

\section{OPEN 6 ACCESS}




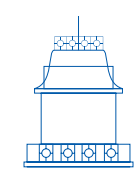

ARTÍCULOS

DE INVESTIGACIÓN

\title{
The leap of thinking: The phenomenological attitude that distances us from the metaphysical wandering
}

\begin{abstract}
Heidegger's late writings make constant allusion to a way of thinking that differs from metaphysics. While in metaphysical thinking we wander away from being, in the new thinking we are only in relation to being. For Heidegger, the only way to get out of the first and reach the second one is through a leap. This paper aims to clarify why there is only one way to access this new way of thinking and to defend that this is the radicalization of the phenomenological maxim. To achieve this goal, the paper characterizes metaphysical thinking as erratic thinking; next, it characterizes the leap, understood as a sudden step to the unconcealment of being; and finally, it presents the consequences of these characterizations and the contrast between them.
\end{abstract}

Keywords: Heidegger, thinking, metaphysics, leap, errancy

\section{Juan Sebastián Ortiz López}

Egresado de filosofía de la Universidad Nacional de Colombia. Magister en Filosofía de la Universidad Nacional de Colombia. Profesor de la Licenciatura en Filosofía de la Universidad Santo Tomás. Miembro del grupo de investigación "La hermenéutica en la discusión filosófica contemporánea", adscrito a los departamentos de Filosofía de la Universidad Nacional de Colombia y de la Universidad de Antioquia. Actualmente participa en una investigación en la Universidad Santo Tomás intitulada: "Alternativas Socio-políticas a la crisis ambiental: Ecosocialismo en Colombia". 
Lo que, por ejemplo, significa nadar nunca lo aprendemos mediante un tratado de natación. Solo el salto al torrente nos dice lo que significa nadar (Heidegger, ¿Qué significa pensar?)

En las lecciones que ofreció en el invierno de 1951 y en el verano de 1952, ${ }^{1}$ recogidas en el texto ¿Qué significa pensar? (en adelante: QSP), Heidegger (2008) se ocupa de una cuestión que ha venido tratando en conferencias y libros que suceden a la publicación de Ser y tiempo (en adelante: ST), y que precisamente aparece en el horizonte que se abre con el replanteamiento de la pregunta por el ser: la concepción y el ejercicio de un pensar alternativo al de la filosofía tradicional, un pensar distinto al metafísico. La ruta escogida para abordar este problema, los pasos dados (en cada lección y entre lecciones) dentro de dicha ruta y la oscuridad que le rodea, evidencian el esfuerzo heideggeriano por asumir la cuestión ya desde un pensar distinto. Esto significa que no solo el contenido del texto, sino también la forma del mismo, da luces, brinda signos, que ayudan al lector (y a quien asistió a las lecciones) a embarcarse en un pensar no-metafísico.

La dificultad más grande y más evidente a la que se enfrenta Heidegger, y también quienes seguimos sus lecciones, es la de no situarse en las perspectivas habituales de la metafísica. Esta dificultad es inherente a la tarea asumida. El horizonte que caracteriza al pensar metafísico alcanza no solo a nuestras reflexiones filosóficas o científicas, sino también a gran parte de las formas en que nos comportamos en, nos referimos a y concebimos nuestra cotidianidad. El leguaje metafísico permea nuestra forma de comportarnos en el mundo, y no es fácil distanciarse de él. De hecho en el artículo "De la esencia de la verdad" (en adelante: DEV), Heidegger (2001) lo caracteriza como un errar inherente a la condición humana.

Buscando sortear esta dificultad, en las lecciones del semestre de invierno Heidegger (2008) se ayuda de una imagen para exponer cómo comprender el paso del pensar metafísico (allí representado por la ciencia) al pensar no-metafísico: "Aquí no hay ningún puente, hay solamente un salto" (p. 19). En las inmediaciones a esta afirmación, Heidegger sostiene que entre la ciencia y el pensar hay un abismo, es decir, que existe una separación tajante entre estas dos formas de comportarse en la realidad. La imagen del salto también aparece en su conferencia "El principio de identidad" (en adelante: PI), y aunque allí varía un poco, pues se concibe como un salto directo al abismo, se mantiene la cuestión central: el salto es la única vía posible para pasar del pensar metafísico a un pensar no-metafísico (a un auténtico pensar) ( $C f$. Heidegger, 1990, p. 77 y ss.).

El objetivo de la presente reflexión es, por un lado, explorar la imagen del salto como única forma de pasar hacia el pensamiento no-metafísico, y por otro, sostener que en esa imagen se pone en evidencia una reinterpretación heideggeriana del enfoque

1 En adelante se denominarán "lecciones del semestre de invierno" y "lecciones del semestre de verano" respectivamente. 
fenomenológico. Para desarrollar esta doble tarea se propone la siguiente ruta: en un primer momento se hará una breve caracterización del terreno desde donde se salta ("El errante pensar metafísico: filosofía, ciencia y cotidianidad"); el objetivo de esas líneas se limita a abrir el horizonte dentro del que Heidegger propone el salto. El siguiente paso será abordar directamente la cuestión del salto, presentando las características que lo convierten en una imagen precisa para ilustrar el cambio de una forma de pensar a otra ("La única forma de salir del pensamiento de vía única”). En tercer lugar se examinará la posibilidad del mismo a pesar del errante comportamiento metafísico, posibilidad que pone de manifiesto el carácter fenomenológico del salto ("El salto como un auténtico comportamiento fenomenológico"). Por último se cerrará leyendo en clave fenomenológica al nuevo pensar y al pensador ("Conclusiones: el salto pensante y el pensar fenomenológico").

\section{El errante pensar metafísico: filosofía, ciencia y cotidianidad}

En QSP, la imagen del salto aparece desde la primera lección. El contexto en que aparece es la polémica que se abre con la afirmación de que en esta época, la época del mayor desarrollo científico conocido, aún no pensamos. Heidegger nos dice:

es cierto que lo dicho hasta ahora, y toda la exposición que ha de seguir, nada tiene que ver con la ciencia, y nada tiene que ver con ella precisamente si nuestra disquisición aspira a ser un pensar [...] La ciencia no piensa [...] Aquí no hay ningún puente, hay solamente un salto [...] nosotros ahora, en cuanto procedemos de las ciencias, hemos de soportar lo escandaloso y extraño del pensar, supuesto que estemos dispuestos al aprendizaje del mismo (2008, p. 19).

Las primeras líneas de esta cita ponen en evidencia que la cuestión del pensamiento es bastante particular, pues al tiempo que se sostiene que tal cuestión debe abordarse pensando, se descarta la posibilidad de su trato desde la perspectiva científica; este abandono de la ciencia se da sencillamente porque esta no piensa. Pero, ¿acaso no pensamos cada vez que hacemos ciencia? De hecho, ¿no pensamos en casi todo momento de nuestra existencia consciente?

Cuando Heidegger dice "la ciencia no piensa", no quiere decir que le falte algo, que sea necesaria una reconsideración de la misma para que comience a pensar. Tampoco quiere decir que la ciencia haya perdido su rumbo, que se haya extraviado en el recorrido hacia su auténtica finalidad. Mucho menos que sea algo de segunda mano, algo sin ningún valor para los hombres. Con esta frase Heidegger dice:

La esencia de los respectivos ámbitos, así en la historia, el arte, la poesía, el lenguaje, la naturaleza, el hombre, Dios, permanece inaccesible a las ciencias. Y a la vez estas caerían constantemente en el vacío si no se movieran dentro de 
sus propios ámbitos. La esencia de tales ámbitos es el asunto del pensamiento (2008, pp. 85-86).

La ciencia no piensa porque su tarea no es preguntarse por su propia esencia. La ciencia está volcada hacia su objeto de estudio, siendo su preocupación solo este y no ella misma. Heidegger (2008) caracteriza este proceder de las ciencias, que no es solo de ellas, como un "pensamiento de vía única", precisamente porque es el objeto de estudio su punto de partida, su meta y su guía. ${ }^{2}$ Aunque es evidente que la labor cotidiana de los científicos (concentrados en su objeto de estudio) se desarrolla como pensamiento de vía única, también es claro que algunos científicos cuestionan aquello sobre lo que trabajan y la forma en que lo hacen. Según parece, estos científicos dirigen su mirada hacia la esencia de su ciencia, tal y como lo haría un teólogo, un artista o un filósofo que también se cuestionase por su campo de trabajo. Heidegger no desconoce esta mirada reflexiva de cualquier intelectual, pero sostiene que dicha mirada sigue enmarcada dentro del pensamiento de vía única, sigue siendo guiada por lo esencial de la forma en que se concibe el objeto de estudio, esencia común a todos los ámbitos del conocimiento: la reflexión se mueve en el ámbito de lo ente sin alcanzar al ser; la reflexión se mantiene en el terreno metafísico.

Decir que "la ciencia no piensa" es otra forma de decir lo ya afirmado en ST, que en ella el ser ha sido olvidado y que la pregunta por el mismo no puede ser siquiera planteada. El tono de esta afirmación no es el de un reproche, sino más bien el de la constatación de una limitación que brota de su esencia metafísica. Esta esencia Heidegger la asocia, en la cuarta lección del semestre de invierno, con el modelo representacional del conocimiento que se ha consolidado desde el pensamiento de Descartes. Mientras nos mantengamos en este modelo no podremos comprender qué es pensar ni podremos pensar efectivamente. Es necesario hacer a un lado la imagen de las “'representaciones' que revolotean en nuestra cabeza” (Heidegger, 2008, p. 35).

En DEV, Heidegger define el "re-presentar" como: "el hacer que la cosa se presente frente a nosotros como objeto" (2001, p. 156). Pero para que esto sea posible, para que la cosa se presente como objeto: "Lo que está enfrente, en cuanto que está puesto así, tiene que atravesar un enfrente abierto y al mismo tiempo detenerse en sí mismo como cosa y mostrarse como algo estable y permanente" (2001, p. 156). Lo presentado, en la representación, tiene que tomarse como algo estable y permanente, y esto solo es posible si hay una apertura previa, un "enfrente abierto", en el que eso presentado puede asumirse como algo que tiene tales características. Heidegger continúa: "Este aparecer de la cosa que se hace patente atravesando el enfrente tiene lugar dentro de un ámbito abierto cuya apertura no es creada por el representar, sino solamente ocupada y asumida por él como ámbito de referencia” (2001, p. 156). Esa apertura

2 Sobre esta forma de caracterizar al pensamiento científico se pueden revisar en QSP Ios hilos conductores que llevan de la lección II a la III y de la III a la IV (ambos hilos corresponden al semestre de invierno). 
previa que hace posible a la representación no proviene de esta, es anterior a ella.

Para comprender qué se quiere dar a entender con esta apertura podemos concentrarnos en la frase "Lo que está enfrente, en cuanto está puesto así". Si está puesto así, significa que hay algo previo que posibilita ese ponerse, e incluso, que cabe la posibilidad de que se ponga de otra manera. La representación ni siquiera pone la cosa de esa manera, constituye un paso posterior. Previo a ella debe darse un ponerse de tal manera, y ese ponerse de tal manera solo es si, a su vez, previamente hay un "lugar" donde las cosas se pueden poner de tal o cual manera. Esto evidencia que el representar es una forma derivada de relacionarse en y con el mundo, que su dominio y privilegio en la época contemporánea no responde a una primacía ontológica (ni siquiera epistémica).

Ahora bien, precisamente porque ya deben cumplirse ciertas condiciones para que el representar pueda darse, este no puede retrotraerse más allá de sí; aquellas condiciones escapan al representar y necesitan de un modo de pensar distinto. En DVE, ese modo de pensar se ilustra a través de una forma de comportamiento denominada Seinlassen (dejar ser), siendo esta una las primeras formas en que Heidegger caracteriza el nuevo pensar. La dificultad de llegar a esta forma de pensar no brota de una "mala costumbre" de los hombres, como si el modo representacional de pensar fuese exclusivamente una cuestión de hábito, sino que se arraiga en lo más profundo de la condición humana.

En el numeral siete de DEV, Heidegger caracteriza el comportamiento humano como esencialmente errante:

Esta inquietud del hombre, que se aparta del misterio para volcarse en lo accesible, y que le hace ir pasando de una cosa a otra, pasando de largo ante el misterio, es lo que llamamos el errar. El hombre anda errante [...] El errar por el que atraviesa el hombre no es algo que, por así decir, se limite solo a rozar al hombre, algo parecido a un foso en el que a veces cayera, sino que el errar forma parte de la constitución íntima del ser-aquí en que se halla inmerso el hombre histórico (2001, p. 166).

El hombre se aparta de aquello que escapa al pensamiento representacionalista, y a la metafísica en general, porque en su esencia está volcarse hacia lo accesible, y andar entre ello. Ese andar, en tanto que pierde de vista el misterio, en tanto que se aleja de la esencia, se caracteriza como un errar. Más allá de la connotación del error como falta o equivocación, errar aquí se comprende desde la perspectiva del comportamiento errante, un deambular de una parte a otra entregado a la ocupación inmediata y sin dar con un lugar de reposo. Que la ciencia no piensa es otra forma de decir que la ocupación científica hace parte del errar, volcándose hacia lo accesible y olvidando el misterio. Tanto el científico, como el artista, el religioso, el filósofo o el ebanista se mantienen en el errar, dado que ni siquiera se percatan del misterio. Este errar, así 
como aquel no-pensar, no es un error para el que haya corrección, es más bien una condición en la que se encuentra el hombre.

Esta caracterización que se ha hecho del errar nos recuerda la caída abordada en ST, ese modo de ser del Dasein en el que, estando-en-el-mundo, está siempre volcado hacia el "mundo" y confundido con él (Cf. Heidegger, 2003c, § 38). Pareciese como si errar fuera otra palabra para nombrar lo mismo que nombra caída. Pues bien, no considero que esto sea así. Mientras que la caída se comprende dentro de los límites del Dasein, ${ }^{3}$ caracterizándose como un modo de ser de este (como un existenzial), ${ }^{4}$ el errar es algo en lo que el hombre siempre está, es primeramente algo en lo que se mueve, y que por esto mismo condiciona sus formas de ser; ${ }^{5}$ el errar, no es una forma de comportamiento del hombre, sino el "espacio abierto" en el que el hombre se comporta sin atender al misterio (Heidegger, 2001, p. 167). ${ }^{6}$

Así pues, es estando fuera del errar que el hombre piensa la esencia de las ciencias y la verdad esencial (Heidegger, 2001). Pero este pensar, en tanto que tiene como tarea lo que es imposible para todo otro tipo de comportamiento en el mundo, es de difícil acceso, especialmente porque dentro de la metafísica no hay herramientas para construir un camino hacia él, ni siquiera se puede prever. De hecho, este pensar no puede entenderse como un puro acto volitivo del hombre, pues no emerge del ser de Dasein sino del misterio; él no consiste exclusiva y primordialmente en un comportamiento humano, sino que es el camino que se abre con el desocultamiento del misterio, camino que implica un comportamiento diferente. Sin embargo, que la metafísica no pueda tender un puente hacia ese pensar no significa que el hombre no pueda acceder a él, pues la esencia del hombre no está en la metafísica, sino en su relación directa con el ser. ¿Cómo pasar del terreno metafísico al pensamiento de su esencia? Heidegger nos dice que a través de un salto.

\section{La única forma de salir del pensamiento de vía única}

Lo primero que resalta de la imagen del salto es su oposición frente a la imagen del puente. El centro de la diferencia entre ambas imágenes se encuentra en que con el puente se defiende la posibilidad de un tránsito libre, en el que los elementos propios

3 "El Dasein solo puede caer porque lo que a él le va es el estar-en-el-mundo por medio del comprender y la disposición afectiva" (Heidegger, 2003c, p. 201).

4 "El fenómeno de la caída pone de manifiesto en forma palpable una modalidad existencial [existenzial] del estar-en-el-mundo" (Heidegger, 2003c, p. 199).

5 "De acuerdo con su carácter abierto y su referencia a lo ente en su totalidad, todo comportarse tiene siempre su manera de errar" (Heidegger, 2001, p. 167).

6 La caída no se presenta como estando en una relación esencial con el ser, sino que es una constitución del Dasein. La caída es un modo de ser del Dasein, mientras que el errar brota del ser y acoge al hombre, al tiempo que permite el desencubrimiento del ente como tal (Heidegger, 2001, p. 167). En la condición de caído el hombre hace ciencia; estando en el errar, andando errante, la ciencia es posible. 
de uno y otro pensar se van difuminando a medida que se pasa de un terreno a otro. Este tránsito es posible gracias a puntos de encuentro en los que ambos tipos de pensar hablan el mismo lenguaje.

En el hilo conductor entre las lecciones I y II del semestre de invierno Heidegger sostiene:

A diferencia de un progreso constante, en el que sin darnos cuenta pasamos de una cosa a otra y todo queda aproximadamente como estaba, el salto nos lleva súbitamente a aquel lugar donde todo es diferente, de modo que allí nos sentimos extraños (Heidegger, 2008, p. 75).

La transición tranquila, en la que los dos terrenos están conectados, no es posible. El paso de un lado a otro conlleva necesariamente un sentimiento de extrañeza; un reconocimiento de que ya no se está en un lugar conocido, y más aún, de que ni siquiera se podía prever a dónde se estaba llegando, pues no se podía ver nada del otro lado al que ahora se ha llegado. De hecho, en PI Heidegger (1990) no nos habla de dos terrenos separados por un abismo sino que sostiene que el salto puede representarse como dirigido hacia el abismo, en la medida en que quien se halla inmerso totalmente en el terreno metafísico no tiene otra forma de representarse cómo es el otro terreno.

Vale la pena señalar entonces que quien ha dado el salto puede reconocer que lo ha dado precisamente por ese sentimiento de extrañeza ya que "en la inevitable habitualidad del ente, el ser [Seyn] es lo más inhabitual; y este extrañamiento del ser [Seyn] no es un modo de aparición del mismo sino él mismo" (Heidegger, 2003a, p. 191). El salto nos lleva directo al terreno del ser, de lo esencial de las ciencias y del hombre mismo. Y como el paso es súbito, es evidente que quien lo da necesitará tiempo para poderse mover en un terreno al que no está habituado. Esta necesidad y aquel sentimiento que brotan de estar ante el misterio, de estar en la pertenencia al ser (Heidegger, 1990, pp. 77 y 79), son consecuencias directas de haber saltado súbitamente y son rasgos distintivos del (nuevo) pensar.

En efecto, frente a la transición tranquila del puente, el salto es un paso súbito, abrupto, brusco. En PI, Heidegger también resalta esa característica del salto: "El salto es la puerta que abre bruscamente la entrada al dominio en el que el hombre y el ser se han encontrado desde siempre en su esencia" (1990, p. 79, cursiva mía). La palabra alemana en ambos textos (QSP y PI) es Jäh que es usada principalmente para indicar algo repentino, es decir, algo que se da sin ser previsto. Que sea repentino no significa que sea inesperado, ni mucho menos azaroso; significa, no solo que es una transición sin mediación, sino también que no hay una completa preparación para esta, que no tenemos pleno control sobre el momento en que se da, y, claramente, que no deja espacio a una previa familiarización con el terreno al que se llega.

En virtud de lo repentino del paso y de la extrañeza que conlleva, Heidegger (2008), ya desde el comienzo de sus lecciones del semestre de invierno -como se ve en la primera cita de la sección anterior -, nos advierte que el salto trae como consecuencia un 
ineludible aprendizaje para moverse en el nuevo terreno, un aprendizaje que comienza por soportar (aushalten) la extrañeza de este nuevo pensar. A mi modo de ver, se trata de soportary no de "aceptar" o "acondicionarse", porque el cambio es tan fuerte que, por un lado los viejos hábitos (el antiguo pensar) vienen a aterrorizar a quien ha saltado y le ponen trabas para moverse en el nuevo terreno, y por otro, porque lo novedoso de este nuevo terreno impacta de golpe. Quizá acá sirva más la manera en que se presenta esta imagen en PI, pues el salto no consiste en superar la diferencia entre uno y otro pensar, no se salta sobre un abismo como si nos librásemos de él; más bien, con el salto nos adentramos en la abismal diferencia que existe entre ambos terrenos (Heidegger, 1990). Esta diferencia apenas se representaba en las inmediaciones previas al salto, pero una vez dado, se aprecia en toda su calidad.

Ahora bien, lo repentino del salto garantiza un paso auténtico de un terreno a otro. Si se salta, si realmente se lo hace, ${ }^{7}$ no hay forma de perder el rumbo del mismo (de extraviarse en la transición). En efecto, en todas las citas sobre el salto presentes en este documento, Heidegger da por sentado que una vez se ha dado ya no hay vuelta atrás, que su ejecución conlleva percatarse de haber llegado a un terreno inexplorado. En Aportes a la filosofía (en adelante: AF), Heidegger dice:

El salto, lo más osado en el proceder del pensar inicial, deja y arroja todo lo corriente detrás de sí y no espera nada inmediatamente del ente, sino que salta antes que todo a la pertenencia del ser [Seyn] en su pleno esenciarse como evento" (Heidegger, 2003a, p. 189).

Que el salto implique una renuncia, un dejar y arrojar todo lo propio del terreno del ente, no significa que con esta imagen Heidegger se retracte del errar presentado en DEV. Dejar todo atrás es poner en suspenso al pensar metafísico (siguiendo lo que sostiene Francis Seeburger en su artículo "Heidegger and the Phenomenological Reduction" (1975). ${ }^{8}$ Para quien salta ya no hay vuelta atrás, porque ya se ha movido dentro del extraño terreno de la pertenencia con el ser, ya esto se le ha abierto y no puede pasar por alto lo allí recorrido. ${ }^{9}$

Si el salto es la única vía para pasar de un terreno del pensamiento a otro, si sus características resaltan la abismal diferencia que existe entre ambos terrenos y si su ejecución conlleva un fuerte rechazo hacia el pensar metafísico, concretamente el pensamiento científico de nuestra era, junto con un aprendizaje que solo puede iniciarse en ese nuevo lugar al que se ha llegado, ¿cómo entender la posibilidad de que estando inmersos en la metafísica podamos prepararnos para el salto y además ejecutarlo?

7 Sabremos bien que no lo hemos hecho si continuamos poniendo objeciones provenientes de la metafísica, tratando de eliminar la extrañeza.

8 En este artículo, Seeburguer defiende que Heidegger nunca abandona realmente la reducción fenomenológica, sino que la comprende de una forma distinta a Husserl, la comprende como el paso hacia el ser.

9 Sobre este abandono, ver las primeras páginas de la lección octava de la Proposición del fundamento (Heidegger, 2003b, p. 92). 


\section{El salto como un auténtico comportamiento fenomenológico}

Para comprender la posibilidad del salto tanto a nivel temático como efectivo, podemos iniciar con la noción de tránsito que Heidegger expone en AF, con la que se describe una etapa previa al salto:

en el tránsito se prepara la decisión más originaria y por ello más histórica, ese $0-0$, al que no queda escondite ni circuito alguno de elusión: o quedar detenido en el fin y su salida, es decir, renovadas variaciones de la "metafísica" [...] o comenzar el otro comienzo, es decir, estar resuelto a su larga preparación (Heidegger, 2003a, p. 190).

El tránsito al salto es una etapa previa que se abre con la consciencia del olvido del ser - Conciencia que no implica haber leído Ser y tiempo. Quien reconoce este olvido se pone en marcha hacia el salto, lo que no significa que realmente salte. En efecto, como se sostiene en la cita, el influjo de la metafísica en su final puede mantener al hombre detenido, errando frente a las puertas del misterio, sin que jamás llegue realmente a comprender lo que la diferencia ontológica es. En cambio, quien da el salto, ya comienza el nuevo comienzo, y piensa de una manera distinta. ${ }^{10}$

En QSP, Heidegger transita con su interlocutor hacia el salto con ayuda del examen de la experiencia que se tiene con un árbol. Heidegger le pide que haga a un lado el modelo representacionalista y se ponga frente al árbol (Heidegger, 2008, pp. 34-35). Sin dicho modelo, el árbol simplemente aparece, se presenta, y el hombre también aparece, se presenta ante el árbol. Heidegger sostiene que si este ejercicio se comprende realmente (lo que no significa que deba comprenderse tan pronto como él lo expone), ya se habrá dado el salto, de ahí que culmine su presentación diciendo: "Detengámonos aquí concentradamente un instante, a la manera como aspiramos con profundidad antes y después de un salto. En efecto, ahora hemos saltado" (Heidegger, 2008, p. 35). Y prosigue:

hemos saltado, hemos salido del círculo usual de las ciencias e incluso, como veremos, de la filosofía. Pero ¿a dónde hemos saltado? [...] Es una cosa sorprendente e incluso terrible que hayamos de saltar al suelo en el que propiamente estamos (Heidegger, 2008, p. 35).

Esta cosa sorprendente y terrible de saltar hacia donde propiamente estamos también es motivo de admiración en PI, allí nos dice:

10 En el acabamiento de la metafísica señalado en ST, en la época del dominio de la técnica, ahora que el "desierto crece" y descubrimos que aún no pensamos, es que se hace posible el tránsito hacia el salto. Este tipo de formulaciones que Heidegger hace en sus distintas obras, lecciones y entrevistas tienen un punto en común: nos encontramos en la época en que el misterio se oculta completamente, y precisamente por ello es que se hace posible el desocultamiento del mismo (esto ya está presente desde DEV). 
El salto es la puerta que abre bruscamente la entrada al dominio en el que el hombre y el ser se han encontrado desde siempre en su esencia [...] Extraño salto el que nos hace ver que todavía no nos detenemos lo suficiente en donde en realidad ya estamos (Heidegger, 1990, p. 79).

¿Cómo entender esa idea de que saltamos al suelo en el que propiamente estamos? ¿Acaso no se ha afirmado que nos movemos normalmente dentro del terreno metafísico? Además, ¿dónde queda la imagen del abismo, si ahora resulta que hemos llegado a nuestro terreno más propio? Precisamente es la referencia a este terreno la que nos da la pista para comprender lo dicho en la primera cita, pues en ella no se dice que saltemos hacia el suelo en el que siempre estamos, o en el que siempre nos movemos, sino "en el que propiamente estamos".

Heidegger no está pasando por alto que el terreno metafísico, donde el hombre anda errante, es el terreno cotidiano. Este propiamente no significa que siempre nos movamos dentro del pensar sin darnos cuenta. Lo que Heidegger quiere decirnos acá es que el terreno del pensar no es uno que trascienda lo cotidiano, sino uno que lo abre de una manera distinta; lo abre, como dice la cita de PI, en su relación con el ser. En efecto, el salto es tal, no porque se atraviese una distancia que separa dos terrenos, sino porque se da un tránsito sin mediaciones de una forma de relacionarse con el ser a otra.

La imagen del abismo se asume de forma distinta según se haya saltado o no. Quien aún se mueve dentro del errar representacionalista no tiene idea de lo que encontrará tras saltar, y entre más se esfuerce por hacerse una idea, más se alejará de la posibilidad de hacerlo. Por otro lado, quien ha saltado asume esto desde una doble extrañeza: se percata de que el abismo se ha desvanecido, pues no se aleja de su cotidianidad (ni la "trasciende"), y sin embargo, reconoce que existe una abismal diferencia entre el errar propio de la cotidianidad y esta otra forma de pensar. De ahí que para Heidegger no haya una forma de representarnos adecuadamente ese suelo en el que propiamente estamos. Aquí solo nos queda saltar. Sin embargo, no hemos de saltar gracias a una fe ciega que tenemos en Heidegger, sino entreviendo precisamente que el modelo representacionalista no logra recoger toda nuestra existencia (Heidegger, 2008, p. 35).

Al hablar de un salto hacia el terreno en el que ya estamos, Heidegger pone en evidencia que la oposición entre la forma de pensar metafísica y la no-metafísica, no conlleva ni una división de la realidad en dos niveles ni una escisión al interior del hombre. De hecho, con ello sigue en sintonía con su versión del hombre como un errante que pasa continuamente por alto el misterio que lo hace posible a él y al mundo. Aquel "propiamente" no es una especie de "estado prometido", un "estado de gracia" que podríamos alcanzar, y que nos libraría del errar metafísico, sino más bien es un acercamiento al misterio y un reconocimiento de que de él brotan hombre, mundo y el errar mismo. El paso es posible a pesar de la diferencia entre uno y otro pensar, en vista de que realmente no se trata del paso de un terreno a otro (como puede concebirse desde la perspectiva representacional), sino de un desvelamiento del terreno en el que propiamente estamos. 
De ahí que el salto se asemeje más a un cambio de actitud en la forma de comportarnos, cambio con el que el terreno donde propiamente estamos se redescubre, se presenta desde una perspectiva completamente nueva. Michel Haar (1993), en una sección dedicada al salto, nos dice: "El salto implica un cambio súbito de registro o de terreno, una forma de ver diferente o desde otro lugar, un nuevo "enfoque", como decimos en fotografía" (p. 95, traducción mía). Pero este no es un cambio cualquiera de enfoque, es un cambio que apunta hacia la mutua pertenencia de hombre y ser. ${ }^{11}$ Se trata de volver a la cosa misma que nos había permanecido oculta.

Aquí ya resuena la máxima fenomenológica “¡A las cosas mismas!". Si el salto es lo que nos lleva al terreno que nos es más propio, el salto se puede comprender como la interpretación radical y la manifestación efectiva de la máxima fenomenológica, máxima que ha servido de guía para el pensamiento heideggeriano. La salida del errante pensar metafísico es una puesta en marcha de la actitud fenomenológica, pero una puesta en marcha que no se puede entender como gradual, como un método con el que se van construyendo puentes hasta llegar a la cosa, sino como un paso repentino a otro terreno y como la manera de moverse en él.

Otto Pöggeler, en El camino del pensar de Heidegger, sostiene que a pesar del cambio que se da en el pensamiento de Heidegger tras ST, el pensador de Messkirch se mantiene pensando siempre en torno a un mismo pensamiento que ve su luz precisamente con esa obra (Pöggeler, 1993, pp. 192-194). ${ }^{12}$ Sin embargo, como también lo hacen otros comentaristas posteriores, Pöggeler resalta que la postura metodológica sobre el trabajo fenomenológico es algo que Heidegger abandonará, en vista de que esta metodología no puede superar su carácter preparatorio, manteniéndose en el terreno de la metafísica:

Es verdad que la mirada fenomenológica intenta poner a la vista los fenómenos e incluso aquello que hace que todos los fenómenos lo sean: el ser mismo; sin embargo, como todo pensar "metafísico", de origen griego, no es libre de inquirir sobre la procedencia esencial del aparecer y del ser, sobre la verdad del ser mismo [...]. A ello se debe que Heidegger abandone la fenomenología, aun cuando ello lo haga solamente con el fin de poder llevar al lenguaje la esencia oculta de lo fenomenológico, la experiencia de la verdad del ser (Pöggeler, 1993, p. 195).

Para Pöggeler el abandono de la fenomenología se da al nivel del proyecto presentado en ST, con el que se esperaba llegar a la tematización de la esencia del ser con ayuda del método fenomenológico. Cuando Heidegger reconoce que este proceder metódico

11 Dahlin (2009) resalta la relación de mutua pertenencia entre pensar y ser que Heidegger expone en PI. Con esto, dice el autor, "Heidegger "ontologiza" el pensar" (p. 3, traducción mía). Para Dahlin esto significa que el pensar no se puede reducir a categorías epistemológicas o biológicas; para mí, esto además abre la posibilidad de comprender dicho pensar fenomenológicamente (si no limitamos "ontologizar" a un campo de investigación temática sobre el ser, sino que lo comprendemos como la realización del desocultamiento).

12 Esto es algo que el mismo Heidegger sostendrá en entrevistas, conferencias y artículos. 
parte del hombre como un proyecto que ya tiene pasos decididos, lo abandona y comienza a hablar de un dejar-ser, de un dejar que la cosa del pensar se presente. Pero, como bien sabemos, esta idea de dejar que la cosa se presente también es la impronta propia del proceder fenomenológico desde antes de ST. ${ }^{13}$ De ahí que para Pöggeler este abandono de la metodología fenomenológica se vea como un dirigirse a la esencia de lo fenomenológico, a la verdad del ser que se desoculta dejándola ser.

En la misma línea, Pablo Veraza sostien que el "Heidegger maduro va a rechazar que en la pregunta por el ser sea adecuado hablar de "tema" o "método" y va a proponer partir de un ámbito de lo abierto en donde se dan los encuentros con las cosas, que llama die Gegend, la región" (Veraza, 2016, p. 105). Junto a esta idea de la región, Veraza menciona algunos apartes del primer tomo de los Cuadernos negros, donde Heidegger expone lo que implica para un pensador asumir un "método" desde que Sócrates acuñó la interpretación que regirá en occidente. Mientras que el "tema" y el "método" se conciben desde la pregunta por el qué (¿qué es?) - pregunta que ya determina el camino a seguir-, die Gegend y el odós (distinto del méthodos) no configuran el preguntar mismo, sino que permiten que las preguntas salgan al encuentro mientras se deja-ser (Veraza, 2016, pp. 105-106).

Así pues, tanto Pöggeler como Veraza defienden que la renuncia al método fenomenológico no es una renuncia a la fenomenología, sino que más bien constituye una radicalización de la misma. Esta radicalización sobresale en, y que se hace efectiva con, la imagen del salto. En efecto, si volvemos una vez más sobre la cuarta lección del semestre de invierno de QSP, podemos dar más fuerza a la idea de que Heidegger no abandona el espíritu fenomenológico a pesar de abandonar el proceder metódico de ST. Cuando Heidegger invita a su interlocutor a apreciar su experiencia con un árbol, es evidente que se dirige a la experiencia misma, la cual ahora se ve de forma distinta a la manera como se le concibe dentro del modelo representacionalista (Heidegger, 2008, pp. 34-35). Saltar es ir directamente a las cosas mismas, volviendo al terreno más propio. El salto no solo es la comprensión de la máxima fenomenológica sino, más importante aún, es la forma radical en que se asume.

Esta radicalización consiste en ir más allá de la postura temática y metódica, es asumir un comportamiento fenomenológico. En su obra Heidegger on Being and Acting, Reiner Schürmann defiende que el pensamiento de Heidegger desemboca en una postura sobre la acción humana y la política completamente anárquica, que rehúye a los principios. Para él, Heidegger reconoce ya desde ST que con la pregunta por el ser se efectúa una modificación en el actuar humano, modificación necesaria para poder comprender lo que se abre con dicha pregunta (Schürmann, 1987, § 40). Shürmann (1987) sostiene que esta postura de Heidegger está influenciada por el pensamiento del Maestro Eckhart, para quien existe un límite en la comprensión de

13 Ver por ejemplo los parágrafos 14 y 15 de Ontología o la introducción de Los problemas fundamentales de la fenomenología. 
ciertos pensamientos, un límite que solo puede cruzarse experimentando aquello que se pretende comprender. ${ }^{14}$ Para mí, esto es lo que nos quiere decir Heidegger en la primera línea de QSP: "Nos adentramos en lo que es pensar cuando pensamos nosotros mismos" (Heidegger, 2008).

La imagen del "salto" es entonces la forma en que Heidegger evidencia que a pesar de haber renunciado al método fenomenológico, nunca renuncia a la máxima propia de la fenomenología. Esta máxima es violentada cuando se construyen planes que pretenden hacerle justicia, pues la única forma de hacerla efectiva es asumiendo un comportamiento que antecede y modifica toda posibilidad de tematización del fenómeno.

\section{Conclusiones: el salto pensante y el pensar fenomenológico}

Para comprender lo que es pensar, para hacerle justicia, debemos estar dentro del terreno del pensar, es decir, es necesario comportarnos de una manera específica, una manera que no es posible bajo el influjo de la metafísica. Pues bien, esta manera solo puede asumirse -solo podemos adentrarnos en ella-con un salto. Saltar es ya pensar (Cf. Heidegger, 2003a, p. 195).

Mientras el fenomenólogo se prepara para su camino, elige sus herramientas y define algunas rutas, el pensador se ve encaminado abruptamente, y las rutas que toma no son preparadas, sino que son las que le salen al encuentro, los senderos que se le van abriendo. El pensador también anda errante como el fenomenólogo, pero a diferencia de este, ha llevado hasta las últimas consecuencias la máxima que los impulsa a ambos, logrando así un distanciamiento del errar. Esta distancia que toma el pensador no es producto de una voluntad dominadora, que le permitiría dar saltos a su antojo (el pensador no dice "hoy pienso y mañana trabajo"), sino que estando dispuesto al pensar, este lo asalta y lo transporta inmediatamente a la pertenencia con el ser, lugar del que en algún momento lo extraerá el errar.

En efecto, la imagen del salto revela que el hombre no se mantiene continuamente en el pensar, sino que llega a él, o está en él, mientras esté dispuesto a saltar y las posibilidades del salto se abran. El salto no se produce una única vez -lo que no significa que la primera vez pierda por eso su carácter de nuevo comienzo. Tal como yo lo veo, si el hombre no puede escapar al errar, y de este al pensar no hay puentes, cada vez que el hombre piensa es porque ha saltado. De ahí que líneas arriba haya sugerido que este nuevo pensar puede comprenderse como una nueva forma de comportarse del hombre en la que el errar queda en suspenso; como si en la radicalización de la actitud fenomenológica se mantuviese la idea de la reducción

14 Sobre la relación entre Eckhart y Heidegger revisar también Castañeda (2012) y Filippi (2003). 
fenomenológica, solo que esta ya no se hace por voluntad metódica, sino que se da en virtud del salto (Cfr. nota 8).

La pura pasividad aparente de esta radicalización fenomenológica -en la que se está en el errar, el salto se da (o nos asalta el pensar), pensar es dejar-ser-, pasa por alto que el hombre debe estar dispuesto para el pensar, y que existe un tránsito para llegar a las inmediaciones del salto. La preeminencia de un lenguaje pasivo después de ST, no elimina el carácter activo del hombre, tampoco lo aminora, sino que lo reinterpreta. El hombre no deja de ser activo en el sentido tradicional, pues nunca escapa del errar, pero en el campo del pensar no puede ser activo de la misma manera. Esta nueva actividad escapa a quienes no piensan. ${ }^{15}$

Quien piensa no es necesariamente alguien que se encierre, pero tampoco es necesariamente el agente de la revolución. Tanto el ermitaño como el revolucionario pueden ser pensadores, pues no es la manera en que se mueve en el errar lo que hace al pensador, sino la disposición a asumir la actitud fenomenológica, la disposición a saltar cada vez que se presente la ocasión. Asimismo, quien piensa puede dialogar con otros, y aunque quizá no se le comprenda plenamente, da visos que invitan a sus interlocutores hacia el pensar, incluso guiándolos por el sendero de la transición al salto. El pensador no puede empujar a otros al pensar, pues el salto lo da cada quien, si está en el camino mismo para saltar. ${ }^{16}$

La radicalidad fenomenológica de este salto al misterio (provocado por él) consiste en que la fenomenología solo se puede ejecutar realmente una vez se salta, en toda otra ocasión se estará o bien en la transición al salto, o bien insistiendo en la metafísica. Asimismo, el pensar solo se puede concebir fenomenológicamente, pues pensar es adentrarse en el desocultamiento de lo que permanece oculto.

\section{Referencias}

Castañeda, J. (2012). Dios y Ser Una aproximación desde Eckhart y Heidegger. Teología Y Sociedad, 9, 107-127. Recuperado de: https://revistas.javerianacali.edu.co/index.php/ teologiaysociedad/article/view/373

Dahlin, B. (2009). On the Path Towards Thinking: Learning from Martin Heidegger and Rudolf Steiner. Studies in Philosophy and Education, 28(6), 537-554 https://doi.org/10.1007/ s11217-009-9147-1

15 De ahí la sorpresa de quienes fueron a visitar a Heráclito al verlo junto a un horno calentándose, y de ahí la invitación a pasar que el pensador les hace, diciéndoles: "También aquí están los dioses" (Cfr. Heidegger, 2006a, pp. 76-78).

16 La agencia del salto es algo que se puede desarrollar con más detalle. Por cuestiones de espacio no es posible hacerlo acá. Buenos guías para este desarrollo son Schürmann (1987) y Haar (1993). 
Filippi, S. (2003). Martin Heidegger y la mística eckhartiana. Invenio, 6(11), 33-39. Recuperado de: https://www.redalyc.org/articulo.oa?id=87761104

Haar, M. (1993). Heidegger and the Essence of Man (W. McNeil, Trad.). Albany: State University of New York Press.

Heidegger, M. (1954). Was heisst Denken? Tübingen: Max Niemeyer Verlag.

Heidegger, M. (1976). Wegmarken. Frankfurt am Main: Klostermann.

Heidegger, M. (1990). Identidad y diferencia (H. Cortés y A. Leyte, Trads.). Barcelona: Anthropos.

Heidegger, M. (2001). De la esencia de la verdad. Hitos (H. Cortés y A. Leyte, Trads.). Madrid: Alianza Editoral.

Heidegger, M. (2003a). Aportes a la filosofía. Acerca del evento (D. Picotti, Trad.). Buenos Aires: Biblos.

Heidegger, M. (2003b). La proposición del fundamento (F. Duque y J. Pérez, Trads.). Barcelona: Ediciones del Serbal.

Heidegger, M. (2003c). Ser y tiempo (J. Rivera, Trad.). Madrid: Trotta.

Heidegger, M. (2006a). Carta sobre el humanismo (H. Cortés y A. Leyte, Trads.). Madrid: Alianza Editorial.

Heidegger, M. (2006b). Identität und Differenz. Frankfurt am Main: Klostermann.

Heidegger, M. (2008). ¿Qué significa pensar? (R. Gabás, Trad.). Madrid: Trotta.

Pöggeler, O. (1993). El camino del pensar de Heidegger (F. Duque, Trad.). Madrid: Alianza Editorial.

Schürmann, R. (1987). Heidegger on Being and Acting: From Principles to Anarchy (C-M. Gros y R. Schürmann, Trads.). Bloomington: Indiana University Press.

Seeburger, F. (1975). Heidegger and the phenomenological reduction. Philosophy and Phenomenological Research, 36(2), 212-221. http://dx.doi.org/10.2307/2107054

Veraza, P. (2016). El pensar del Ereignis de Heidegger como otra fenomenología. Método e inicio del camino. Franciscanum, 58(165), 89-116. http://doi.org/10.21500/01201468.2184 